\title{
Characteristics of Thinking Processes abstraction Reflective of Students in Solving limits Problems
}

\author{
Patma Sopamena ${ }^{1,2}$, Toto Nusantara ${ }^{1}$, Edy Bambang $\operatorname{Irawan}^{1}$, Sisworo ${ }^{1}$ \\ ${ }^{1}$ Post Graduate University of Malang \\ ${ }^{2}$ Department of Mathematics Education IAIN Ambon
}

\begin{abstract}
This research was aimed to describe the thinking processes of students in problem solving limits by reflective abstraction. This research was classified as exploratory research with qualitative descriptive approach. Subjects of this research were 21 students of IAIN Ambon and Pattimura University of Ambon. The data of test results or problem-solving task limit function by incorporating student think aloud and interviewing transcripts. The combination of these data further was created a structure diagram of thinking that is based on study framework according to Piaget by the researchers. The results showed that: 1) Track student thinking in solving the problem limits by construction of study is the path of the ordered most of the track: $1-2-1-3-2$ $-4-3-1-4-2-3$. and 2) Characteristics of the thinking processes of students in solving problems limit based construction study with lines that are not consistent can be explained as follows: the activities of reflection occurs in the absence of coordination process between the components of cognitive structure is already complete.
\end{abstract}

Keywords: characteristics, Thinking Processes, Reflective Abstraction, lines of thought, limits problem.

\section{Introduction}

Abstraction and generalization are the two most important aspects of mathematical thinking (Bochner, 1966, as cited in Kaput \& Schorr, In Press). Similarly, a constructivist theory often supports the idea of this abstraction level. Abstraction consists of two levels which the relationship between the deductions of mathematical knowledge can be built. The first level is called the primary level. At this level, the connection relationship information that was built at the level of the more abstract in which the information is represented. It means, the relationship is no more abstract than the information that connects them. Some relationships are built on a more abstract level higher from pieces of information that called reflective level. Hiebert and Lefevre (1986, p 4-5) in White \& Mitchelmore (2007) describes both of these levels:

It is useful to distinguish between two levels at which relationship between pieces of mathematical knowledge can established. One we will call primary. At this level the relationship connecting the information is constructed the same level of abstractness (or at a less abstract level) than that at which the information itself is represented. That is, the relationship is no more abstract than the information it is connecting. Some relationships are constructed at a higher, more abstract level than the pieces of information they connect. We call this the reflective level. Relationships at this level are less tied to specific contexts. They often are created by recognizing similar core features I pieces of information that are superficially different. The relationships transcend the level at which the knowledge currently is represented, pull out the common features of different looking pieces of knowledge, and tie them together. Piaget distinguished three types of abstraction, they were; empirical abstraction, pseudo-empirical abstraction, and Reflective Abstraction. According to (Beth \& Piaget, 1966, p.188 - 189) in Dubinsky (1991) found empirical Abstraction is the knowledge derived from the properties of objects. This means that knowledge can be gained from the experiences that arise. Pseudoempirical abstraction is intermediate between empirical and research and teases out properties that the actions of the subject have introduced into objects. Reflective abstraction described by Piaget called general coordination (general coordination) of actions and, as such, its source is the subject and it is completely internal. This kind of Abstraction leads to a very different sort of generalization which is constructive and results in 'new syntheses in midst of which particular laws acquire new concept".

Reflective abstraction is a very important concept in mathematics education. Reflective abstraction (Dubinsky, 1991) is a concept introduced by Piaget to describe the construction of the structure of mathematical logic by an individual during cognitive development. Two important observations that were conducted by Piaget was, the first, that study has no absolute beginning but from an early age in the structure of sensory motor coordination (Beth \& Piaget, 1966, p. 203-208) and the second, that the study continues until it reached higher mathematical concepts which is required by a person to fill the entire history of the development of mathematics. It can be considered an example of the process of reflective abstraction (Piaget, 1985, p.149-150, in Dubinsky 1991). Furthermore, according to Cooley (2002) in Capetta (2007), reflective abstraction is mechanism to isolate certain properties of mathematical structure that allows the subject to construct or 
reconstruct new knowledge. From the opinion above the reflective abstraction that is defined in this research is a concept that describes construction mathematical structures logically (logic-mathematical structures) by individuals. The study about reflective abstraction completes an investigation of such an idea epistemological barriers learned by Cornu \& Sierpinka (in Dubinsky, 2002), or the conflict between the shadow concept and definition of the concept are investigated by Schwarzenberger \& Tall (1978); Tall \& Vinner (1981); Dreyfus \& Vinner (1982); Vinner (1983); Tall (1986a); Vinner \& Dreyfus (1989). Some people think reflective abstraction as an attempt to explain what something happen, while others try to explain why the idea did not occur.

Further research on the reflective abstraction level mathematical thinking has further studied among others by Ayers et al (1998); Paschos \& Farmaki (2006); Cappetta (2007). Ayers, Davis, Dubinsky and Lewin (1988) conducted a study of college students collaborate on topic compositions function. This research obtained the following results: 1) constructions in abstraction reflective learners do not happen automatically, 2) the use of computers in teaching abstract concepts can help provide concrete experience and also can bring mental processes construction by Piaget called the abstraction reflective. 3) computer-assisted learning is more effective in bringing about the construction of the reflective abstraction compared with the given traditional learning experience. Paschos \& Farmaki (2006) conducted a research in such the case study on Mary, a first-year student majoring in mathematics with problems that are given related to the integral course and continued with the interview. The result of research was found that all construction in reflective abstraction (interiorization, coordination, encapsulation, reversal, and generalization) appeared on Maria when she was solving problems related with integral.

Capetta (2007) conducted a study on the concept of reflective abstraction by topic limit. Kind of quasi experimental study. The aim of this study is to see if the design already prepared can bring mental processes in the construction of reflective abstraction (interiorization, coordination, encapsulation, and generalization). Qualitative results are good in the experimental class and control class, there are students who do the complete construction (5 constructions) and there are also students who do not complete construction (less than 5 construction). The studies above only examine the emerge of construction process kinds in reflective abstraction that almost all of them preceded by interiorization and ended with generalizations without seeing the path of construction that can be passed in children's thinking process. This study will describe the type of student thought processes in solving the problem limits by reflective abstraction, followed by analyzing the construction lines of reflective abstraction.

\section{Construction Kind of Reflective Abstraction}

Piaget (in Pashcos \& Farmaki 2006) distinguished reflective abstraction construction into four types: (a) interiorization, as the internal construction process, which is how to define the phenomenon that is perceived; that is, when "a series of actions translate the material into an operating system interiorized" (Piaget, 1980, p. 90). Dubinsky (1991, p. 107), argued that "interiorization allowed people to become aware of the actions, to reflect and to combine with other actions". (b) Coordination or composition of two or more processes to build a new one. (c) Encapsulation or conversion from the process (dynamic) become an object (static), in the sense that, "... the actions or operations into objects are thematized from mind or assimilation" (Piaget, 1985, p. 49). (d) When the subject learns to apply the existing scheme for the collection of a broader range of symptoms, then we say that the scheme has been generalized. Generalization can also occur when the process is formulated to the object. The scheme will remain the same except that it now has wider application. Piaget called these reproductive assimilation or generalization (Piaget, 1972, p.23) and he called extensional generalization (Piaget \& Garcia, 1989, p. 299) in Paschos (2007).

Piaget (in Paschos, 2006) distinguished four types of reflective abstraction construction process, they are: interiorization process, coordination, encapsulation, and generalization. Researchers described the components of reflective abstraction based on the description and indicator, as shown in Table 1. Further elaboration of these indicators are used to analyze the thinking process of students in solving problems limit.

Table 1. Indicators problem solving limits by reflective abstraction

\begin{tabular}{|c|c|c|}
\hline $\begin{array}{l}\text { Reflective Abstraction } \\
\text { Components }\end{array}$ & description & Indicator \\
\hline
\end{tabular}




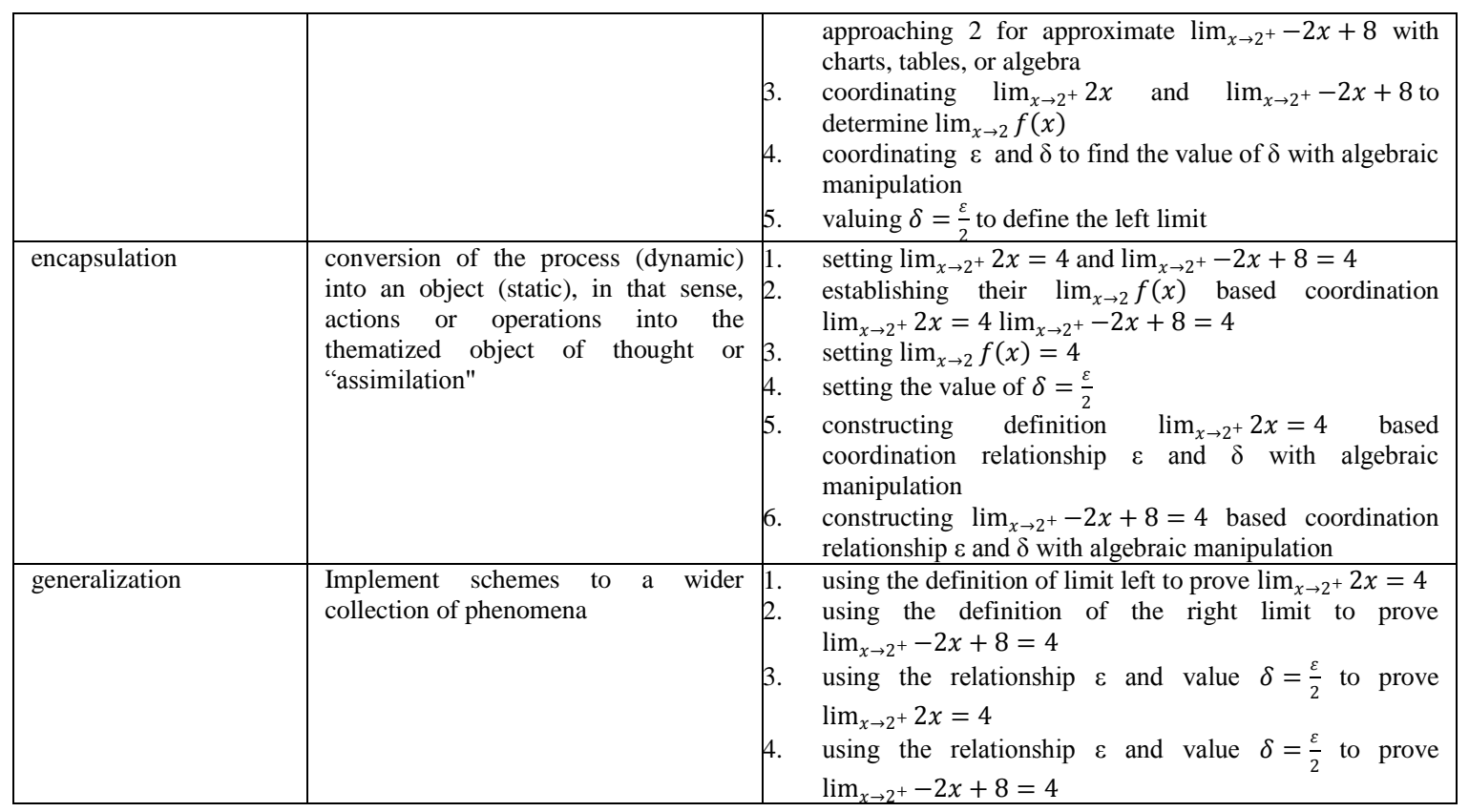

Subject

\section{Methods}

The subjects were 36 students of IAIN Ambon and Pattimura University in Ambon. They currently are in fourth and sixth semesters. By choosing the subject, it is expected to limit the timing of their material studies and have been mastered properly.

\section{Instrument}

Because of the research was qualitative, the main instrument is the researchers themselves an, limit problems and interviews as an additional instrument. Limit problems studied in this research is the issue limit through the construction of "limits unilaterally". Construction "limits unilateral" implicit in the issue as follows:

Is known $f(x)= \begin{cases}2 x & x<2 \\ 5 & x=2 \\ -2 x+8 & x>2\end{cases}$

a. Investigate whether $\lim _{x \rightarrow 2} f(x)$ there? Determine the value?

b. If there prove your statement using the definition of limit!

From the issue of limit function above, when subjects were solving the problems they were exposed to the limit unilaterally (left limit and right limit). Subjects must complete one-sided limits and determine the limit values of each of the left limit and right limit. Furthermore, from the value of unilateral limits, subject will conclude that the limit of the function exists or not. Because of this issue suggests that the limit function exists, then subjects should be able to determine the value of one-sided limits are equal. Then, using the formal definition $(\varepsilon-\delta)$, the subject prove the existence of the limit function. In addition to completing in narration forms, subjects could also indicate that the limit value by using graphics or tables (numerical).

\section{Procedure}

At the first stage, students completed the instrument given in a way think aloud in the allocated time. The results of their work were corrected to see how their work and which one was correct. Only subjects which their work result were not optimal will proceed to the next step was, researchers conducted interviews to understand the thought process by reflective abstraction. The process of the research was recorded by using a handy cam. Furthermore, researchers analyzed the possible paths of thought processes and characteristics based on the construction of reflective abstraction.

\section{Data analysis}

This research is a qualitative descriptive exploratory approach. At the step of data analysis stage, Activities carried out by the researchers were 1) copying the data obtained from the think aloud and interview, 2) reducing the data, including descriptions, choosing subject matter, focusing on the important things, removing unnecessary, and organize raw data obtained from the field, 3) coding the data of the answer sheet problems limit and interviews based on indicators of abstraction reflective (table 1), After that, in this study, 
subjects who did the track thinking process of abstraction reflective sequence, that was the path that began the process of 1 (interiorization) - 2 (coordination) - 3 (encapsulation) - 4 (generalization), and subjects who performed track thinking process of reflective abstraction ordered in part, namely track: $1-2-1-3-2-4-3$ $-1-4-2-3$, and so on. 4) explaining the thinking process in solving the problem limits by reflective abstraction, and 5). Conclusion.

\section{Results And Discussion}

Researchers asked 36 students to solve the problems of limit. The total of 15 students were not working optimally, but when they were given the opportunity for reflection, 21 students were not optimal finished the issue, but after given the opportunity for reflection, they could finish properly. After obtaining the raw data, from 8 students who did the thinking process sequences partially reflective abstraction with the same characteristics. The next explanation was about one S1, it was S1 did thinking process with construction sequences partially reflective abstraction. In the thinking process S1 based work, think aloud, and interviews were obtained type of the construction process was inconsistent, i.e lane construction: $1-2-1-3-2-4-3-$ $1-4-2-3$ in this research, due to the leap or displacement in the construction process of reflective abstraction. However, the structure of thinking S1 was already complete, although in the process of resolving the problem, an error occurred. After given the opportunity for reflection, S1 realized the mistake and then made improvements to obtain correct answers and improve the structure of thinking.

\subsection{Thinking Processes S1}

When S1 asked to solve the problem, S1 can understand the problem, and finish it until the end. In solving the problem, S1 settlement does not reflection step even though the process is wrong. After given the opportunity to reflect S1 realize the mistakes and make improvements. The structure of the thought process S1 can be seen in diagram 1 below:
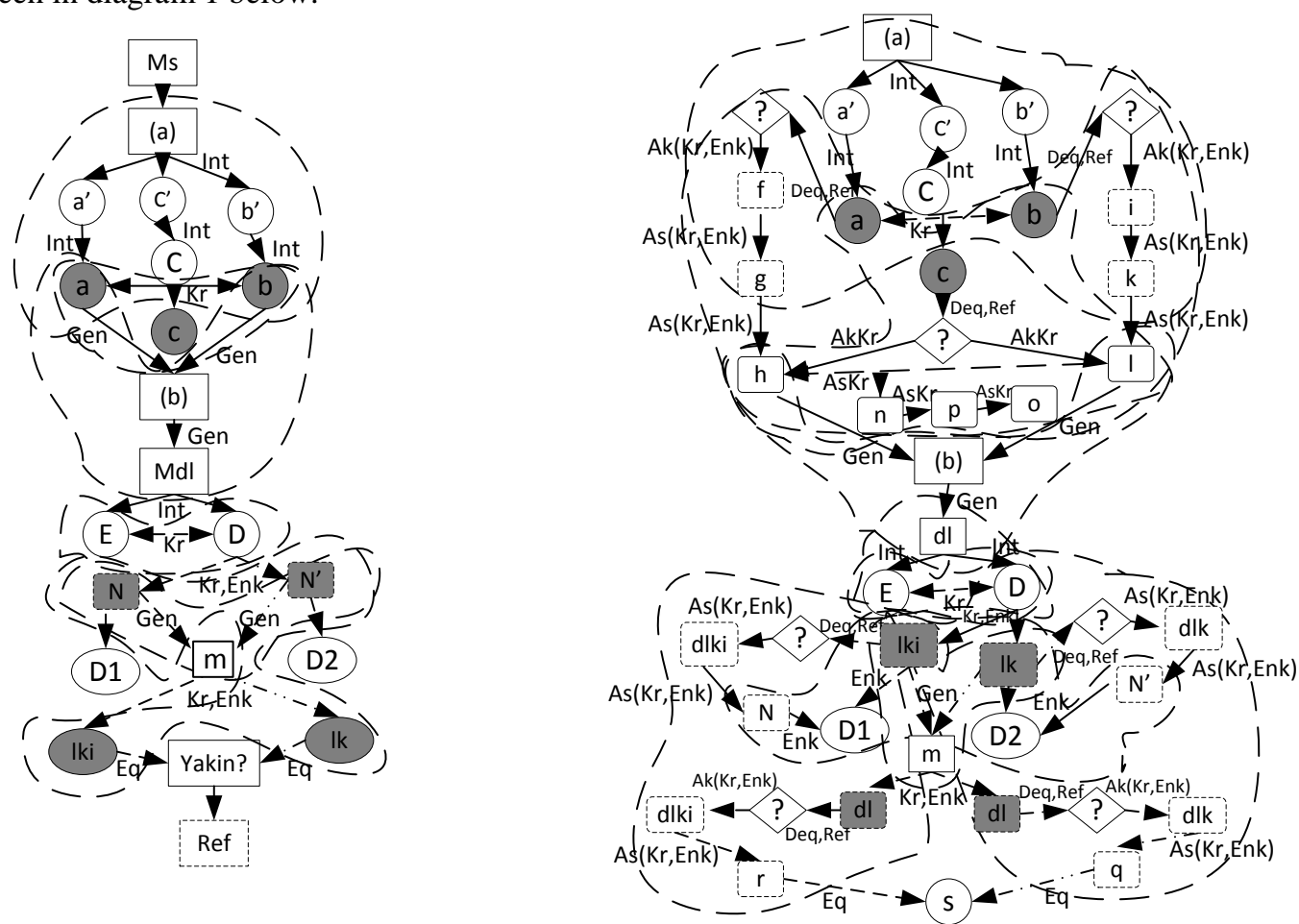

The thinking structure before reflection

The thinking structure after reflection

Diagram 1 Structure of Thinking Processes of S1

4.2 The Thinking Line of S1 in solving limit problems with reflective abstraction construction.

When the S1 solved the problems thinking structure S1 is already completed. Although in the problem solving process S1 made mistakes, but after being given the opportunity to reflect S1 award of the error and corrected it. The thinking process of S1 in solving the problem based on the construction of reflective abstraction can be seen in chart 2 below. 


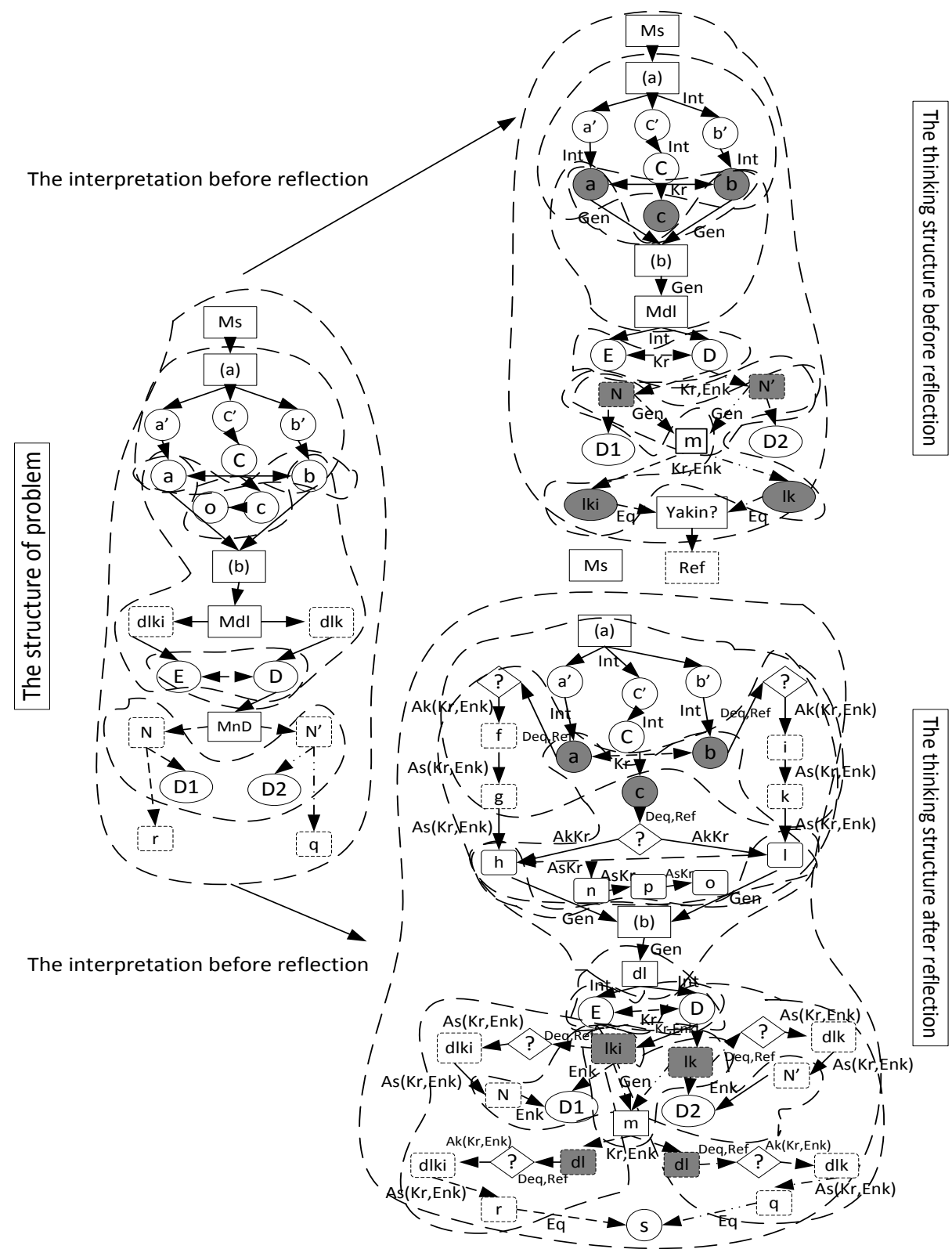

Diagram 2 Structure of Thinking of S1 in solving problems of Limit with the Reflective Abstraction Construction

\section{Information:}

\begin{tabular}{|c|c|c|c|}
\hline Code & Description & Code & Description \\
\hline Ms & Problem & (a) & Investigate the limit \\
\hline $\mathrm{a}^{\prime}$ & $f(x)=2 x$ & $\mathrm{a} \& \mathrm{~h}$ & $\lim _{x \rightarrow 2^{-}} 2 x=4$ \\
\hline $\mathrm{b}^{\prime}$ & $f(x)=-2 x+8$ & b\&l & $\lim _{x \rightarrow 2^{+}}-2 x+8=4$ \\
\hline $\mathrm{C}^{\prime}$ & $f(x)=5$ & $\bar{C}$ & $\lim _{x \rightarrow 2} 5=5$ \\
\hline $\mathrm{c}$ & $\lim _{x \rightarrow 2^{-}} 2 x=4=\lim _{x \rightarrow 2^{+}}-2 x+8$ & o & $\lim _{x \rightarrow 2} f(x)=4$ \\
\hline (b) & Prove $\lim _{x \rightarrow 2} f(x)=4$ & Mdls & Using the definition of limit unilaterally \\
\hline dlki & $\begin{array}{l}\text { Definition of left limit: } \\
\begin{aligned} \forall \varepsilon>0, \exists \delta>0 \ni 0< & <(2-x)<\delta \\
& \Rightarrow|2 x-4|<\varepsilon\end{aligned}\end{array}$ & $\mathrm{dlk}$ & $\begin{array}{l}\text { Definition } \quad \text { of right limit: } \\
\begin{aligned} \forall \varepsilon>0, \exists \delta & >0 \ni 0<(x-2)<\delta \\
& \Rightarrow|(-2 x+8)-4|<\varepsilon\end{aligned}\end{array}$ \\
\hline E & $\varepsilon>0$ & $\mathrm{D}$ & $\delta>0$ \\
\hline $\mathrm{N}$ & $\begin{aligned}|2 x-4| & =|(-2)(2-x)| \\
& =|-2||(2-x)| \\
& =2(2-x)\end{aligned}$ & $\mathrm{N}^{\prime}$ & $\begin{aligned}|(-2 x+8)-4| & =|-2 x+4| \\
& =|(-2)(x-2)| \\
& =|-2||(x-2)|\end{aligned}$ \\
\hline
\end{tabular}




\begin{tabular}{|c|c|c|c|}
\hline & $=(2-x)<\frac{\varepsilon}{2}$ & & $\begin{array}{l}=2(x-2) \\
=(x-2)<\frac{\varepsilon}{2}\end{array}$ \\
\hline D1 & $\delta=\frac{\varepsilon}{2}$ & D2 & $\delta=\frac{\varepsilon}{2}$ \\
\hline $\mathrm{r}$ & $\begin{aligned} \therefore \forall \varepsilon>0, \exists \delta=\frac{\varepsilon}{2} & >0 \ni 0<(2-x) \\
& <\delta \Rightarrow|2 x-4|<\varepsilon\end{aligned}$ & $\mathrm{q}$ & $\begin{aligned} \therefore \forall \varepsilon>0, \exists \delta=\frac{\varepsilon}{2} & >0 \ni 0<(x-2) \\
& <\delta \\
& \Rightarrow|(-2 x+8)-4| \\
& <\varepsilon\end{aligned}$ \\
\hline $\mathrm{MnD}$ & Finding the value of delta & $\mathrm{m}$ & prove \\
\hline $\mathrm{i}$ & $\begin{array}{l}\text { Make a chart or graphic/ table function } \mathrm{f} \\
(\mathrm{x})=-2 \mathrm{x}+8 \text { for } \mathrm{x}>2 \text { with test points } \mathrm{x} \\
=2,1 ; 2,2 ; \ldots\end{array}$ & $\mathrm{f}$ & $\begin{array}{l}\text { Make a chart / table function } \mathrm{f}(\mathrm{x})=2 \mathrm{x} \\
\text { for } \mathrm{x}<2 \text { with test points } \mathrm{x}=1,88 ; 1,98 \text {; } \\
\ldots\end{array}$ \\
\hline $\mathrm{k}$ & $\begin{array}{l}\text { Obtained that more } x \text { close to } 2 \text {, the } \\
\text { value of } f(x) \text { gets closer to } 4 \text { from the } \\
\text { right }\end{array}$ & $\mathrm{g}$ & $\begin{array}{l}\text { Provided that the more } x \text { close to } 2 \text {, the } \\
\text { value of } f(x) \text { is getting closer to the } \\
\text { fourth from the left }\end{array}$ \\
\hline$?$ & disequilibrium occurs & $\mathrm{n}$ & Using the rules of unilateral limits \\
\hline $\mathrm{p}$ & No limit & & process interiorization \\
\hline$\rightarrow \rightarrow$ & The process of proving the left limit & & Generalization process \\
\hline$\Rightarrow$ & The process of proving the right limit & & encapsulation process \\
\hline & $\begin{array}{l}\text { Coordination } \\
\text { encapsulation }\end{array}$ & Int & Interiorization \\
\hline$\underset{t \rightarrow}{t}$ & The coordination process & $\mathrm{Kr}$ & Coordination \\
\hline Enk & encapsulation & Gen & Generalization \\
\hline
\end{tabular}

From the chart 2 above, the thinking process line of S1 in solving limit problems with reflective abstraction construction can be seen in chart 3 below:

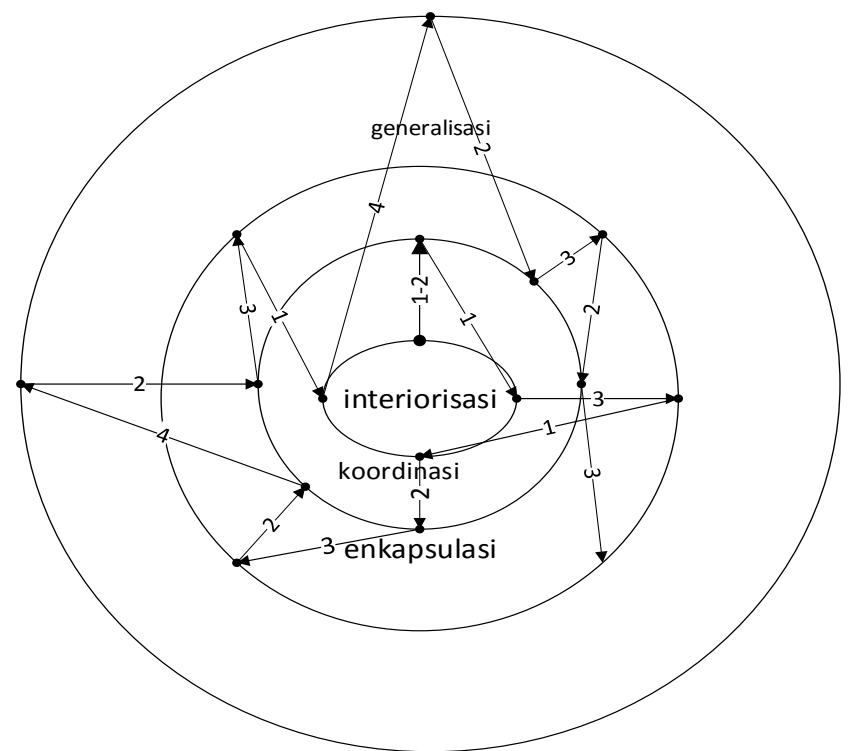

Diagram 3 Thinking Line of S1 in solving problems of limit with the Reflective Abstraction construction

\section{Information:}

$\rightarrow:$ Start the construction process

$\longrightarrow$ : Line construction

1 :interiorization

2 :coordination

3 :encapsulation

4 : generalization

Before to solving the problem, S1 started the solving process by reading, observing and identifying the problems which allowed $\mathrm{S} 1$ to take action on the problems faced, problem to be solved is limit which function is combination of three discontinuous functions. As stated by $\mathrm{S} 1$ as follows:

S: on this matter known to the function $f(x)=2 x$ for $x<2, f(x)=5$ for $x=2$, and the function 
$f(x)=-2 x+8$ for $x>2$. We were told for the first probe whether the limit of $f(x)$ for $x$ close to 2 that there is, what is it worth, and secondly if the limit were told to prove.

This process is interiorization construction process in which the $\mathrm{S} 1$ construct the internal processes in order to understand the phenomenon that is perceived. Then, $\mathrm{S} 1$ performed direct substitution by entering $\mathrm{x}=2$ in $\mathrm{f}(\mathrm{x})$ as the estimated $\lim _{x \rightarrow 2} f(x)$ in this case S1 performed the treatment in the third joint function, but at this stage S1 made mistakes, i.e S1 did not consider the domain of the three functions. After some reflection S1 realized and fixed it along with creating graphics function, then $\mathrm{S} 1$ coordinated the process of incorporating the value of $\mathrm{x}$ approaching 2 into three functions to approach $\lim _{x \rightarrow 2} f(x)$, namely $\lim _{x \rightarrow 2^{-}} 2 x, \lim _{x \rightarrow 2} 5$ and $\lim _{x \rightarrow 2^{+}}-2 x+8$ along with checking the graph $\mathrm{f}(\mathrm{x})$, to determine whether $\lim _{x \rightarrow 2} f(x)$ there or not. S1 was confused because of the $\mathrm{f}(\mathrm{x})=5$ so the $\mathrm{S} 1$ separated it into $\lim _{x \rightarrow 2^{-}} 2 x=4, \lim _{x \rightarrow 2} 5=5$, and $\lim _{x \rightarrow 2^{+}}-2 x+$ $8=4$, but upon reflection, realized that because $\lim x \rightarrow 2 f(x)$ can be seen from the limits of unilateral $\left(\lim _{x \rightarrow 2^{-}} 2 x=4\right.$ and $\left.\lim _{x \rightarrow 2^{+}}-2 x+8=4\right)$ so $\lim _{x \rightarrow 2} f(x)$ was exist namely $\lim _{x \rightarrow 2} f(x)=4$. As exploration work of $\mathrm{S} 1$ as follows:

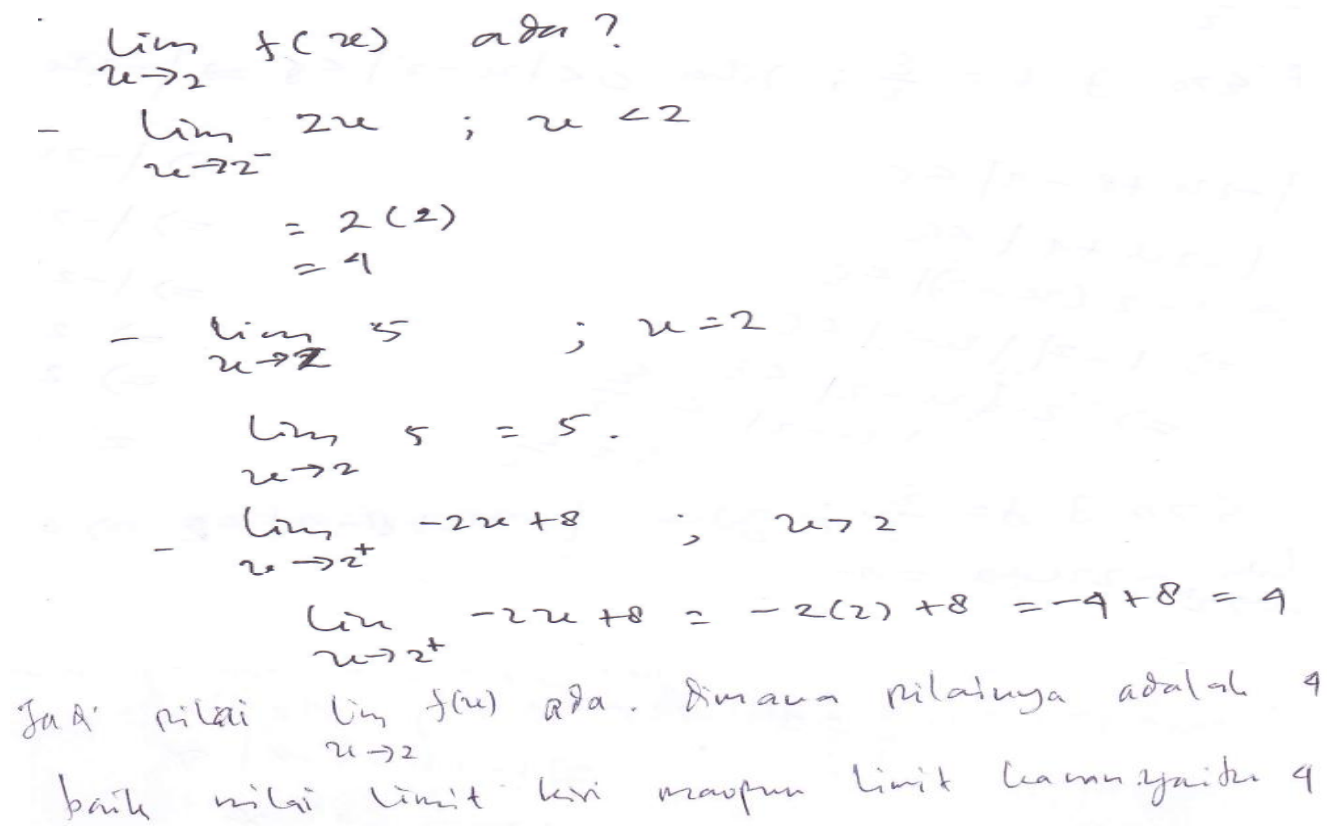

Figure 1 Exploration work of S1 of in investigating the existence of limit

Reinforced with interview excerpts as follows:

$I \quad$ : are you sure with substitution $x=2$ to $f(x)$ ?

S1 : silence (as he takes his job)

I $\quad$ : look again to function and work, how is it?

S1 : This function consists of three, namely $f(x)=2 x$ for $x<2, f(x)=5$ for $x=2$, and

$f(x)=-2 x+8$ for $x>2$.

$I \quad:$ Now what does the function $f(x)=2 x$ for $x<2$ ?

S1 : the value of the function $f(x)$ depending on $x<2$, ie all $x$ less than 2 such as $1,0,-1,-2$, and so on (as he moved his hand to the left).

$I \quad$ : how the function $f(x)=5$ for $x=2$ and $f(x)=-2 x+8$ for $x>2$ ?

S1 : same, for $f(x)=5$ where $x=2$, the value $f(x)$ it remains 5 because of the constant. While $f(x)=-2 x+8$ for $x>2$ value function depends on $x>2$, ie all $x$ greater than 2 , for example 3, 4, 5, and so on (as he moved his hand towards the right).

I : OK, if $x<2$ and $x>2$ just move on integers only?

S1 : no ma'am, for $x<2$ to $1.9 ; 1.8 ; 1.7 ; 1.6$; and so on until the negative. While for $x>2$ to $2.1 ; 2.2 ; 2.3$; etc. ( $S 2$ wrote in a table, counting and muttering case value function $S 1$

Create graphs of functions)

I : are you sure?

S1: yes ma'am, I'm sure

I :Okay, now take a look the value of the function in the graph (S1), what can you say?

S1 : (notice the graph) is getting closer $x$ to 2 on the left and the right value function closer to 4. 
At this stage, S1 performed coordination process line $\rightarrow$ interiorization $\rightarrow$ encapsulation (before reflection), followed by interiorization $\rightarrow$ coordination $\rightarrow$ encapsulation $\rightarrow$ coordination (after reflection).

Furthermore, S1 thought to prove that $\lim _{x \rightarrow 2} f(x)=4$. In this step S1 started with the process of generalization that is by using the definition of limit to prove $\lim _{x \rightarrow 2^{-}} 2 x=4$ and $\lim _{x \rightarrow 2^{+}}-2 x+8=4$, although at this stage S1 made a mistake, S1 should have used the left definition limit or right one. As S1 did when S1 when left to prove limit as follows:

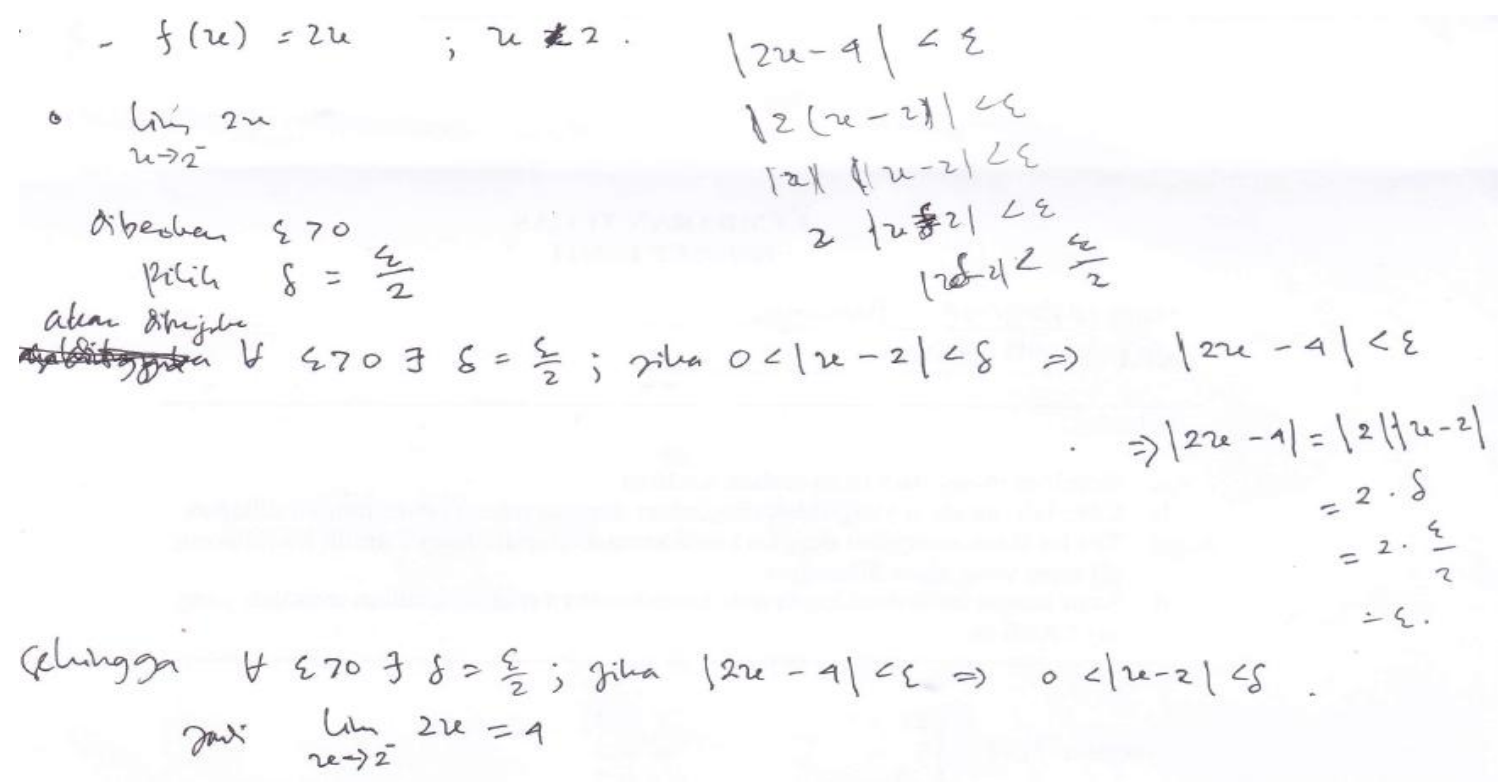

Figure 2 Exploration work of S1 in proving right limit

But after being given the opportunity for reflection, the subject is awared of the error and corrected it. The subject then constructed the definition of limit for $\lim _{x \rightarrow 2^{-}} 2 x=4$ and $\lim _{x \rightarrow 2^{+}}-2 x+8$ by first look for value $\delta$. To find the value of delta subject performed algebraic manipulations such as work on the subject, and set $\delta=\frac{\varepsilon}{2}$. S1 thus obtained that $\forall \varepsilon>0, \exists \delta>0 \ni 0<(2-x)<\delta \Rightarrow|2 x-4|<\varepsilon$ (definition left limit) and $\forall \varepsilon>0, \exists \delta>0 \ni 0<(x-2)<\delta \Rightarrow|(-2 x+8)-4|<\varepsilon$ (definition left limit), then it is evident that $\lim _{x \rightarrow 2^{-}} 2 x=4$. At this stage, S1 performed generalization line process $\rightarrow$ coordination $\rightarrow$ encapsulation (before reflection), followed by interiorization $\rightarrow$ generalization $\rightarrow$ coordination $\rightarrow$ encapsulation $\rightarrow$ coordination $\rightarrow$ encapsulation (after reflection).

\section{Conclusion}

Based on the results of theoretical study and discussion of this study concluded that

1. The student line of thinking in solving the limit problems based in reflective abstraction construction is partial sequences line started from interiorization process to coordination then back again to interiorization then move to encapsulation to once again to coordination and then interiorization and then jumped to generalization to coordination and further to encapsulation

2. The characteristics of the students thinking processes in solving limit problems based on reflective abstraction construction with lines that are not consistent can be explained as follows: a) the activities of investigation occurs because of incomplete cognitive structure. An important component in the form of a unilateral definition of limit does not exist in the cognitive structure. b) the activity of doing reflection occurs because there is no coordination process between the cognitive structure component which is already complete.

\section{Reference}

[1]. Ayers, T., Davis, G., Dubinsky, E., \& Lewin, P. 1988. Computer Experiences in Learning Composition of Function. Journal for Reasearch in Mathematics Education, 19(3): 246 - 259.

[2]. $\quad$ Cappetta, R.W. Reflective Abstraction And The Concept Of Limit: A Quasi Experimental Study To Improve Student Performance In College Calculus and Curriculum Initiates. Makalah disajikan pada Conference of American Mathematical Assosiation of TwoYear Collegee (AMATYC), Minniapolis, 3 Nopember (http://c.ymcdn.com/sites/www.amtyc.org/resource/resmgr/2007_Conference_Proceedings/cappetta07.pdf) diakses tanggal 6 Januari 2015

[3]. Clark, D. A. 2014, The Wiley Handbook of Cognitive Behavioral Therapy, First Edition. New York, NY: Guilford Press.

[4]. Cornu, B. (1991). Limits. In D. Tall (Ed.), Advanced Mathematical Thinking. (pp.153-166). Boston: Kluwer. 
[5]. Creswell, J. W. (2009). Educational Research: Planning, Conducting, and Evaluating Quantitative and Qualitative Research (4rd ed.). Thousand Oaks, CA: Sage.

[6]. DeVries, D. (2001). RUMEC/APOS Theory Glossary. Retrieved May 22, 2007, from http://www.cs.gdu.edu/ rumec.Papers/glossary/html

[7]. Dreyfus, T. \& Vinner, S. 1982. Some Aspects of The Function Concept in College Students and Junior High School Teachers. Makalah disajikan pada the $6^{\text {th }}$ Conference of the International Group for the Psychology of Mathematics Education, Antwerpwn, $22-28$ Juli 1982

[8]. Dubinky \& Lewin, P. Reflective Abstraction an Mathematics Education: The Genetic Decomposition of Induction and Compactness,

[9]. Dubinsky (2002). Genetic Decomposition of There Scemas. Dalam D. Tall (Ed), advanced Mathematical Thinking (hlm. 109 116). New York: Kluwer Academic Publisher.

[10]. Dubinsky, Ed (1991), "Reflective Abstraction In Advanced Mathematical Thinking," in Advanced Mathematical Thinking, Tall, David (ed.), pp.95-123, Kluwer Academic Publishers, Boston, MA.

[11]. Kaput, J.J. \& Schorr, R.Y. (in press). Changing representational infrastructures changes most everything: the case of SimCalc, algebra and calculus. In K. Heid and G. Blume, (Eds.), Research on the impact of technology on the teaching and learning of mathematics.

[12]. Mitchelmore, M., \& White, P. (2007). Abstraction in mathematics learning. Mathematics Education Research Journal,19(2), 1-9.

[13]. Paschos, T. dan Farmaki.V. 2006, The Reflective Abstraction in the construction of Concept of The definite integral: A Case Study. International Group for The Psychologi of Mathematics Education. Vol. 4, p.337-344, Prague: PME. 4-337

[14]. Schwarzenberger, R.L. \& Tall, D. 1978. Conflicts in the Learning of Real Numbers and Limits. Mathematics Teaching, 82: 44 - 49.

[15]. Tall, D. \& Vinner, S. 1981. Concept Image and Concept Definition in Mathematics With Particular Reference to Limits an Continuity, Educational Studies in Mathematics, 12(2): 151 - 169.

[16]. Tall, D. 1986a. Building and Testing a Cognitive Approach to the Calculus Using Computer Graphics, Ph.D. Thesis: Mathematics Education Research Centre, University of Warwick.

[17]. Vinner, S. \& Dreyfus, T. 1989. Images and Definition for The Concept of Function. Journal for Research in Mathematics Education. 20 (4): 356 - 366

[18]. Vinner, S. 1989. Concept Definition, Concept Image and the Notion of Function. International Journal of Mathematical Education in Science and Technology, 14: 239 - 305 